\title{
Development of Si-SiC Hybrid Structures for Elevated Temperature Micro-Turbomachinery
}

\author{
Hyung-Soo Moon, Dongwon Choi, and S. Mark Spearing, Member, ASME
}

\begin{abstract}
The design of the Massachusetts Institute of Technology (MIT) microengine is limited in part by the material capability of Si primarily due to the pronounced thermal-softening and strain-softening at temperatures higher than the brittle-to-ductile transition temperature (BDT), approximately $550{ }^{\circ} \mathrm{C}$. In order to circumvent this limitation, it has been proposed to reinforce the $S i$ with chemical vapor deposited (CVD) $\mathrm{SiC}$ in strategic locations to create a $\mathrm{Si}-\mathrm{SiC}$ hybrid microengine turbine spool. Detailed design of $\mathrm{Si}-\mathrm{SiC}$ hybrid structures for high temperature micro-turbomachinery, however, has been hampered by the lack of understanding of the mechanical behavior of $\mathrm{Si}$ and $\mathrm{SiC}$ hybrid structures at elevated temperatures and by the unavailability of accurate material properties data for both $\mathrm{Si}$ and $\mathrm{SiC}$ at the temperatures of interest. In this work, a series of initial thermomechanical FE analyzes have been performed to assess the advantage of the hybrid structures, and to provide structural design criteria and fabrication requirements. Then, the feasibility of the $\mathrm{Si}-\mathrm{SiC}$ hybrid structures concept for elevated temperature micro-turbomachinery was verified based on more rigorous mechanical testing at high temperatures. Finally, the $\mathrm{Si}-\mathrm{SiC}$ hybrid spool design was critically reevaluated with regard to creep using a Si constitutive model developed as a separate effort.

[0988]
\end{abstract}

Index Terms-Finite element analysis, mechanical testing, Massachusetts Institute of Technology (MIT) microengine, Si-SiC hybrid structures.

\section{INTRODUCTION}

$\mathbf{S}$ INGLE crystal silicon, the material of choice for the first MIT (demonstration) microengine [1], exhibits strong thermal-softening behavior at temperatures higher than its brittle-to-ductile transition temperature (BDT), approximately $550{ }^{\circ} \mathrm{C}$. This thermal softening behavior limits the turbine inlet temperature, which in turn significantly degrades the overall engine efficiency. Thus, the strategy employed in the all-silicon demonstration engine [2], [3] was to design the rotor so that there is a high heat flux from the turbine rotor to the compressor to keep the wall temperature of the turbine rotor below $650{ }^{\circ} \mathrm{C}$, at which temperature the Si yield strength is on the order of 250 $\mathrm{MPa}$. This strategy, while permitting a workable demonstration device, has a severe negative impact on the engine efficiency and power output.

Manuscript received January 13, 2003; revised August 15, 2003. This work was supported by ARO MURI under Contract DAAG55-98-1-0292. Subject Editor C.-J. Kim.

H.-S. Moon and S. M. Spearing are with the Department of Aeronautics and Astronautics Engineering, Massachusetts Institute of Technology, Cambridge, MA 02139 USA (e-mail: hsmoon@mit.edu; spearing@mit.edu).

D. Choi is with the Department of Material Science and Engineering, Massachusetts Institute of Technology, Cambridge, MA 02139 USA (e-mail: dwchoi@mit.edu).

Digital Object Identifier 10.1109/JMEMS.2004.832182
In order to improve the microengine's performance, the heat flux from the turbine into the compressor must be reduced by introducing a thermal barrier structure between the turbine and compressor. Decreasing the heat flux, however, implies that the turbine wall temperature may increase higher than silicon can withstand. In order to circumvent this limitation, it has been proposed to reinforce the $\mathrm{Si}$ with chemical vapor deposition (CVD) $\mathrm{SiC}$ in strategic locations to create $\mathrm{Si}-\mathrm{SiC}$ hybrid structures for elevated temperature micro-turbomachinery [4], [5]. The proposed conceptual design of a $\mathrm{Si}-\mathrm{SiC}$ hybrid rotor structure is shown schematically in Fig. 1. The rationale that led to this structural design has been discussed in more detail together with preliminary structural analyzes and its contributions to the overall engine performance in [6]. While this previous work has assessed the potential of the $\mathrm{Si}-\mathrm{SiC}$ hybrid structures for improving engine efficiency as well as maintaining structural integrity, it has not accounted for the effects of the pronounced strain-softening and creep of $\mathrm{Si}$ at elevated temperatures and high stresses. Furthermore, the stress concentration within a part made of single crystal Si exhibiting the strain-softening behavior may accelerate and propagate the localized deformation, as pointed out by Walters [7], [8].

This paper focuses on developing a self-consistent design for $\mathrm{Si}-\mathrm{SiC}$ hybrid structures for elevated temperature micro-turbomachinery, powerMEMS, given the constraints imposed by microfabrication processes and system considerations. In Section II, a brief description of the status of the Si-SiC microfabrication process is presented. Section III presents a series of initial thermomechanical $\mathrm{FE}$ analysis results for $\mathrm{Si}-\mathrm{SiC}$ hybrid structures to assess the feasibility of the hybrid structures, and to provide structural design criteria and fabrication requirements. Materials and structures issues associated with the mechanical characteristics of $\mathrm{Si}$ at elevated temperatures in the development of $\mathrm{Si}-\mathrm{SiC}$ hybrid structures for micro-turbomachinery are also addressed. In Section IV, the feasibility of the Si-SiC hybrid structures concept for elevated temperature micro-turbomachinery is verified based on rigorous mechanical testing at high temperatures. Finally, the $\mathrm{Si}-\mathrm{SiC}$ hybrid spool design is critically re-evaluated with regard to creep using an Si constitutive model developed as a separate effort.

\section{Si-SiC MiCROFABRICATION PROCESS}

$\mathrm{SiC}$ has been identified as the most promising candidate for use as a refractory structural material due to its high stiffness, strength, and chemical stability at elevated temperatures [9], [10]. However, techniques for microfabricating single crystalline $\mathrm{SiC}$ to the high level of precision required for the microengine are not yet available primarily due to the lack of 


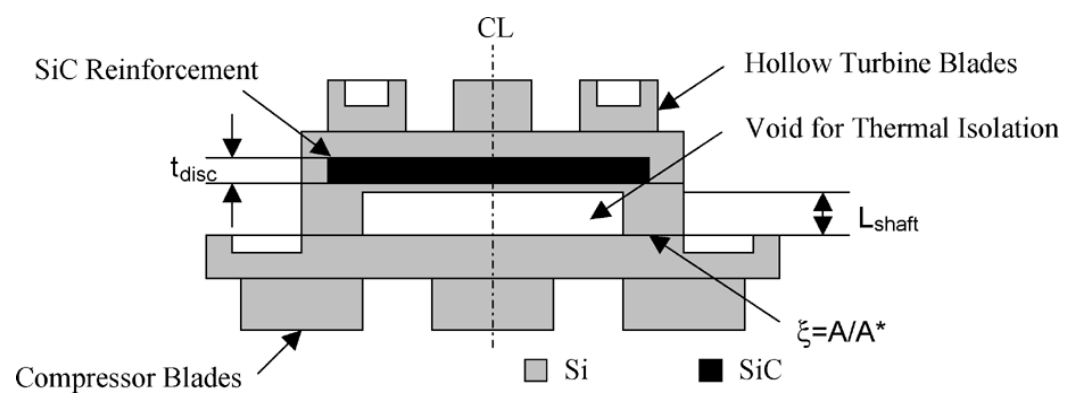

Fig. 1. Cross section of the proposed conceptual design of a Si-SiC hybrid rotor. Critical dimensions and parameters are shown.

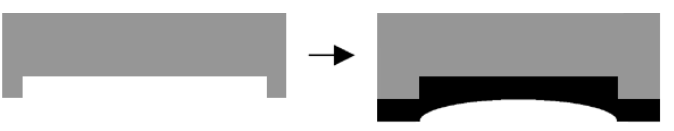

Etch Disc $\quad$ CVD SiC

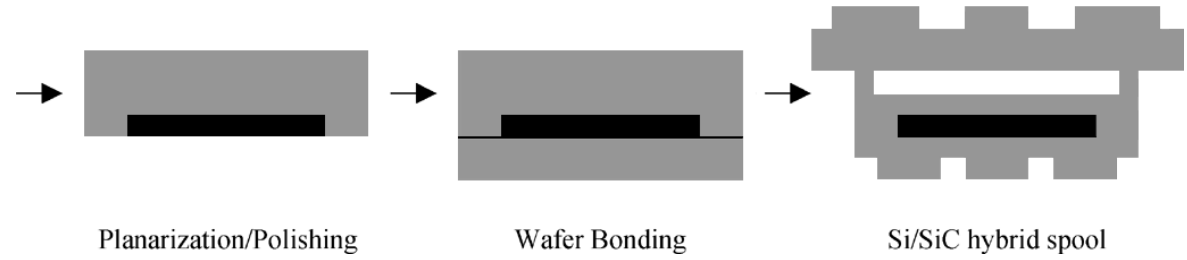

Fig. 2. Si-SiC hybrid spool process steps.

precise and fast $\mathrm{SiC}$ etching techniques. To circumvent this limitation, CVD of polycrystalline $\mathrm{SiC}$ coatings on silicon wafers has been utilized to fabricate the $\mathrm{Si}-\mathrm{SiC}$ hybrid structures. The necessary process steps required for the $\mathrm{Si}-\mathrm{SiC}$ hybrid turbine structures are outlined in Fig. 2. CVD SiC is deposited on pre-patterned silicon wafers and the wafers with thick $\mathrm{SiC}$ coatings are then fabricated into turbine rotors by post-CVD processes such as wafer planarization, wafer bonding, and deep-reactive ion etching (DRIE).

\section{A. LPCVD SiC and Residual Stress Control}

CVD SiC is deposited on $100 \mathrm{~mm}$, n-type, (100) silicon wafers by the thermal decomposition of vaporized methyltrichlorosilane (MTS) using hydrogen as a carrier gas at elevated temperatures and subatmospheric pressures according to the following chemical reaction [5], [11], [12]:

$$
\mathrm{CH}_{3} \mathrm{SiCl}_{3}+\alpha \mathrm{H}_{2} \rightarrow \mathrm{SiC}+3 \mathrm{HCl}+\alpha \mathrm{H}_{2}
$$

where $\alpha$ is the molar ratio of $\mathrm{H}_{2}$ to $\mathrm{CH}_{3} \mathrm{SiCl}_{3}$. The deposition temperature is around $1000^{\circ} \mathrm{C}$ at which polycrystalline $3 \mathrm{C}-\mathrm{SiC}$ with a zinc-blende structure is produced. $\mathrm{SiC}$ films produced at different temperatures and deposition rates have different grain sizes of approximately $50-200 \mathrm{~nm}$. However, all the SiC films show columnar microstructures with a strong preferred orientation of (111) plane. Various systems and growth procedures for CVD SiC have been reported elsewhere [13]-[16]. Material characterization has shown that CVD SiC meets the major property requirements for the microengine such as high strength and conformality. The most critical issue in the $\mathrm{SiC}$ deposition is residual stress control. Controlling residual stresses by changing
CVD process variables properly is of critical importance to all the $\mathrm{Si}-\mathrm{SiC}$ hybrid structure fabrication steps since a high level of residual stress can cause wafer cracking during the deposition and planarization as well as excessive wafer bow, which is detrimental to the subsequent planarization and bonding processes. The stress development in the polycrystalline CVD SiC is associated with the presence of thermal and intrinsic stress components. Thermal stress develops in the SiC film during cooling to room temperature after deposition due to the thermal mismatch between the $\mathrm{SiC}$ and the $\mathrm{Si}$ substrate. Intrinsic stresses are associated with the microstructures determined by the material deposition and growth. One has more control of intrinsic stresses versus thermal stress simply because not much can be done about the thermal expansion coefficients of materials. Therefore, the basic concept of residual stress control is to balance the intrinsic stress components with the thermal stress component by modifying properly the CVD process parameters such as source gas ratio and deposition temperature. More details on the residual stress control in CVD SiC can be found in [11], [12], [17].

\section{B. SiC Planarization and Wafer-Level Bonding Using Interlayer Material}

Following $\mathrm{SiC}$ deposition, unnecessary parts of the SiC coatings are removed by planarization and polishing processes prior to bonding. For good wafer bonding, it is required to achieve a high degree of surface smoothness after planarization. In the case of Si-Si wafer bonding, it has been observed that the roughness of wafer surfaces should be less than about $10 \AA$ [18]. The surface finishing of $\mathrm{SiC}$ is much more challenging because of its very high hardness and chemical stability. Due to the chemical inertness of SiC, Chemical Mechanical Polishing 
(CMP) is not yet available to improve the surface smoothness of $\mathrm{SiC}$ to the level adequate for direct wafer bonding. Therefore, the current planarization technique adopted in this research uses only mechanical polishing with a diamond grit. However, use of a diamond grit unavoidably results in a rough hill-and-valley-like surface structure, which cannot meet the requirements for successful wafer-level bonding. To circumvent this problem, interlayer materials must be deposited on the rough surface of the polished $\mathrm{SiC}$ to fill the grooves introduced by the grinding/polishing processes. A CVD silicon oxide has been used as such an interlayer material, but oxide CMP is still necessary since the as-deposited surface of the CVD oxide is not smooth enough for direct wafer bonding either. Following the oxide CMP, $\mathrm{H}_{2} \mathrm{O}_{2}$-based standard RCA wet cleaning process is performed to remove any organic and metallic contaminants on all the surfaces to be bonded. The RCA cleaning also makes the wafer surfaces hydrophilic, which is required to facilitate spontaneous bonding upon wafer contact before finalizing the bonding process by high temperature annealing.

\section{Si-SiC Hybrid STRUCTURES FOR MICRO-TURBOMACHINERY}

As an extension of Miller's preliminary analysis [6], the structural analysis for the microengine focused on predicting the maximum operating temperature that the proposed hybrid structures could withstand and assessing the benefits from the spool design from the point of view of the overall engine efficiency. This section also addresses an assessment of the potential problems associated with the mechanical behavior of $\mathrm{Si}$ at elevated temperatures which have not previously been considered in detail.

\section{A. Preliminary FE Analysis of Hybrid Turbine Rotor}

Three-dimensional FE simulations for a hybrid turbine rotor have been performed with a refined FE model combining the turbine disc and blade as shown in Fig. 3 in order to verify the previous structural analysis by Miller [6], where the hybrid turbine blade and disc were considered as separate bodies. The FE mesh was created using a commercial pre-/post-processing package, MSC/PATRAN [19], and analyzed using ABAQUS STANDARD [20], a commercially available finite element package. A relative $\mathrm{SiC}$ thickness of $30 \%$, the ratio of the $\mathrm{SiC}$ layer thickness against the $\mathrm{Si}-\mathrm{SiC}$ hybrid disc thickness, was incorporated in the turbine rotor disc in between $\mathrm{Si}$ disc layers. This is consistent with the projected capabilities of the $\mathrm{SiC}$ deposition process. While $\mathrm{SiC}$, whose melting point is $3000^{\circ} \mathrm{C}$, was assumed to behave elastically throughout the temperature range (up to $900{ }^{\circ} \mathrm{C}$ ), the material model for $\mathrm{Si}$ was assumed to be elasto-plastic as modeled by ABAQUS STANDARD PLASTICITY with no strain-hardening/softening behavior. The thermal softening behavior of $\mathrm{Si}$ was described with the yield strength decreasing with increasing wall temperature according to

$$
\sigma_{Y}=-A^{*} T+B
$$

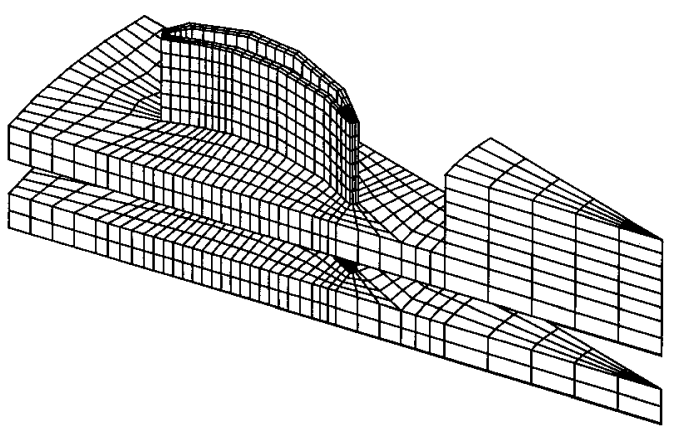

(a)

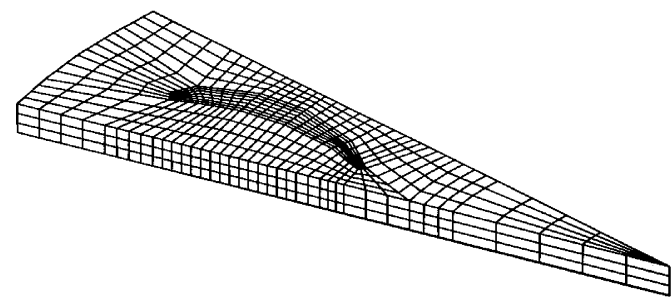

(b)

Fig. 3. Refined FE model for blade and disc (a) FE mesh for the Si and (b) FE mesh for the SiC.

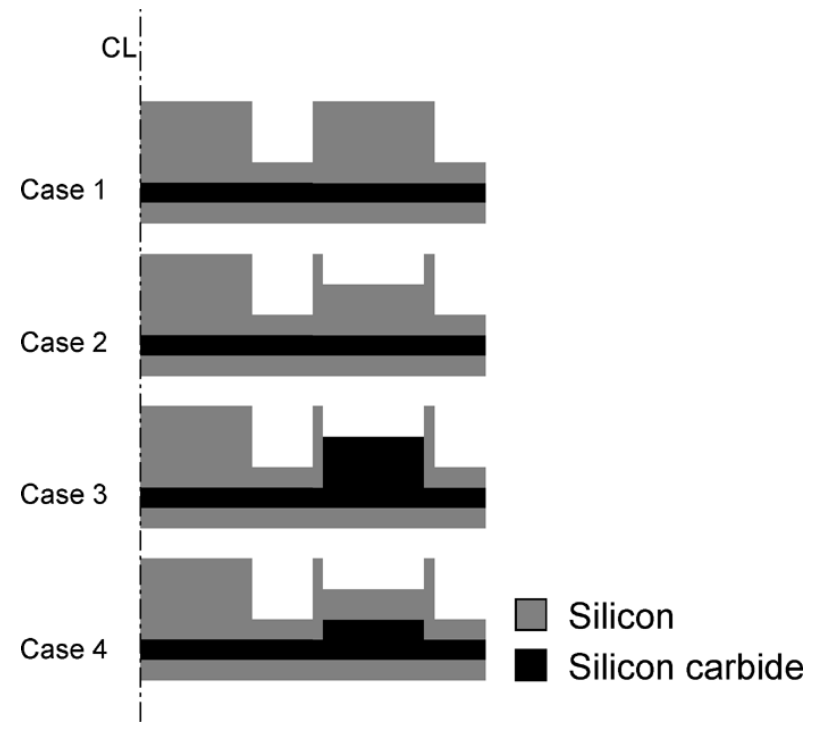

Fig. 4. Geometrical configurations considered in the analysis.

where $\mathrm{A}$ and $\mathrm{B}$ are the linear fit coefficients. Values of $A=$ $0.652 \mathrm{MPa} / \mathrm{K}$ and $B=806.3 \mathrm{MPa}(500<T<1220 \mathrm{~K})$ were used in the present analysis [6], [21]. Assuming that the periodic boundary condition has little influence on the overall deformation and stress fields of the rotor, only one twentieth of the turbine rotor was modeled. For simplicity, the thermal barrier (hollow shaft) was modeled as a linear spring.

As illustrated in Fig. 4, the geometrical configurations considered here were as follows:

1) solid silicon blade and disc reinforcement with $30 \% \mathrm{SiC}$;

2) all-silicon hollow blade with a half-height inner core and disc reinforcement with $30 \% \mathrm{SiC}$;

3) hybrid $\mathrm{Si}-\mathrm{SiC}$ hollow blade with a half-height $\mathrm{SiC}$ inner core and disc reinforcement with $30 \% \mathrm{SiC}$; 
TABLE I

SuMMARY OF FE CALCULATIONS OF THE Si-SiC HyBRID TURBINE ROTOR

\begin{tabular}{lccccc}
\hline \multicolumn{1}{c}{ Case } & $\begin{array}{c}\text { Max. } \\
\text { Temp. } \\
{\left[{ }^{\circ} \mathrm{C}\right]}\end{array}$ & $\begin{array}{c}\text { Max.stress } \\
\text { in SiC } \\
{[\mathrm{MPa}]}\end{array}$ & $\begin{array}{c}\text { Max. radial } \\
\text { expansion } \\
{[\mu \mathrm{m}]}\end{array}$ & $\begin{array}{c}\text { Max. } \\
\text { tangential } \\
\text { deflection } \\
{[\mu \mathrm{m}]}\end{array}$ & $\begin{array}{c}\text { Max.vertical } \\
\text { deflection } \\
{[\mu \mathrm{m}]}\end{array}$ \\
\hline $\begin{array}{l}\text { Solid Si blade }+30 \% \mathrm{SiC} \\
\text { disc }\end{array}$ & 890 & 514 & 2.2 & 1.8 & 4.6 \\
$\begin{array}{l}\text { All Si hollow blade }+30 \% \\
\text { SiC disc }\end{array}$ & 905 & 509 & 2.1 & 2.0 & 4.0 \\
$\begin{array}{l}\text { Hollow Si blade w/ 50\% } \\
\text { SiC core + 30\% SiC disc }\end{array}$ & 920 & 644 & 2.4 & 1.6 & 5.8 \\
$\begin{array}{l}\text { All Si hollow blade w/ SiC } \\
\text { post up to blade root }+30 \%\end{array}$ & 905 & 510 & 2.0 & 1.7 & 3.9 \\
SiC disc & & & & & \\
\hline
\end{tabular}

${ }^{*}$ Stress and deflection values are obtained at the corresponding maximum temperature.

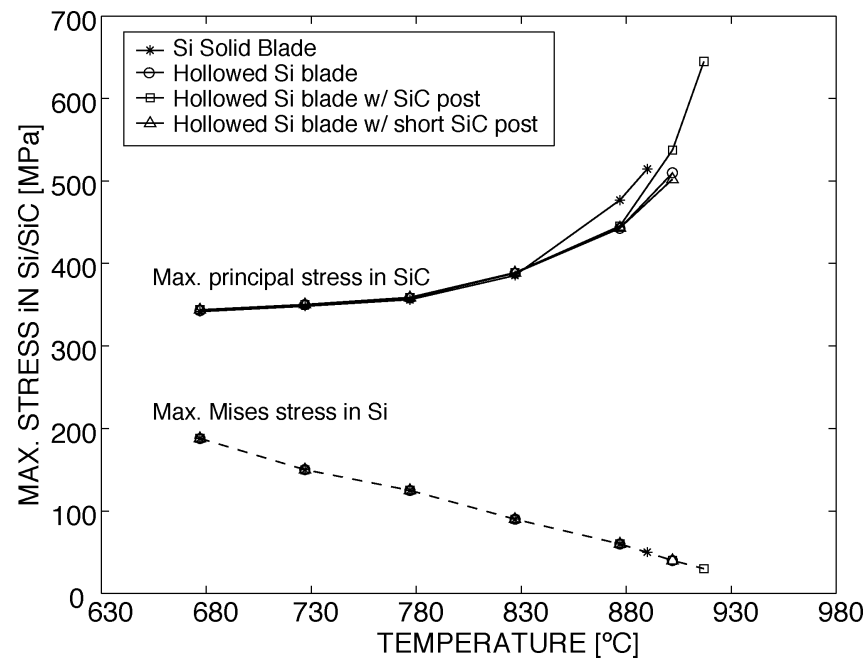

Fig. 5. Maximum stresses in the $\mathrm{Si}-\mathrm{SiC}$ hybrid turbine rotor of four design configurations.

4) all-silicon hollow blade with a half-height inner core and $\mathrm{SiC}$ post up to blade roots and disc reinforcement with $30 \%$ $\mathrm{SiC}$.

Fig. 5 shows how the maximum stresses for each case vary as the temperature increases. The results are summarized in Table I. This refined 3-D FE simulation correlates well with the previous hybrid disc and blade analysis by Miller [6] in terms of the prediction of the maximum turbine wall temperature that the hybrid structure can withstand. In conclusion, the FE simulation results confirm the potential of the hybrid structure concept for improving engine efficiency. Although there is little difference in the achievable maximum operating temperature among the four cases, Case 2 (all-silicon hollow blade and disc reinforced with $\mathrm{SiC}$ ) stands out as a prospective candidate for the hybrid turbine rotor when microfabrication difficulties are taken into account.

\section{B. Thermomechanical FE Analysis of Turbine Rotor}

The structural analysis results in the previous section were obtained assuming uniform temperature in the turbine rotor, which is a reasonable assumption, given the low Biot number of ap- proximately 0.02 . The isothermal assumption, however, may not be valid when there is a heat sink (i.e., the compressor) that gives rise to a high thermal gradient. Thus, in order to identify any hot spots in the structure that may cause a catastrophic failure when combined with high local stresses, a 3-D thermomechanical FE analysis has been performed using the same FE mesh. It is critical that accurate thermal boundary conditions, which are not always readily available, be applied in the analysis. The thermal boundary conditions shown in Fig. 6 were based on the previous analysis [21] and the CFD results [22]. For simplicity, the thermal barrier structure (hollow shaft) is again modeled structurally as a linear spring.

As is clear in Fig. 7(a), the temperature distribution of the turbine rotor with a shaft/ring of $1.5 \mathrm{~mm}$ inner radius, $100 \mu \mathrm{m}$ wall thickness, and $600 \mu \mathrm{m}$ shaft length, shows a considerable temperature gradient. The highest temperature occurs at the tip of the blade and the lowest at the area adjacent to the shaft end. Fig. 7(b) and (c) show the effective stress and effective plastic strain, respectively, corresponding to the temperature field. While the high stress state of the $\mathrm{SiC}$ in the center indicates that the centrifugal inertial load is carried mostly by the $\mathrm{SiC}$ reinforcement, the high stress in the $\mathrm{SiC}$ reinforcement below the blade trailing edge is caused by the bending moment due to the blades. The plastic strain developed on the surface of the turbine rotor disk shown in Fig. 7(c) implies that the elastic material around the deformed zone is still sufficient to support the centrifugal loading.

\section{Structural Analysis of Thermal Barrier}

The small Biot number of the rotor implies that in order to improve the engine efficiency a significantly low thermal conductance $\left(1 / R_{\mathrm{th}}=k_{\mathrm{th}} A^{*} / L\right.$, where $k_{\mathrm{th}}$ is the thermal conductance of $\mathrm{Si}, A^{*}$ the area that contacts with the rotor, and $L$ the length of the shaft) is required. This in turn may compromise the overall strength of the structure. In addition the difficulties associated with the deep etching process for the journal bearing face and wafer bonding process impose severe geometrical constraints on the achievable wall thickness and shaft length. For simplicity, the turbine blades and compressor blades were modified so as to apply the equivalent bending moment to 


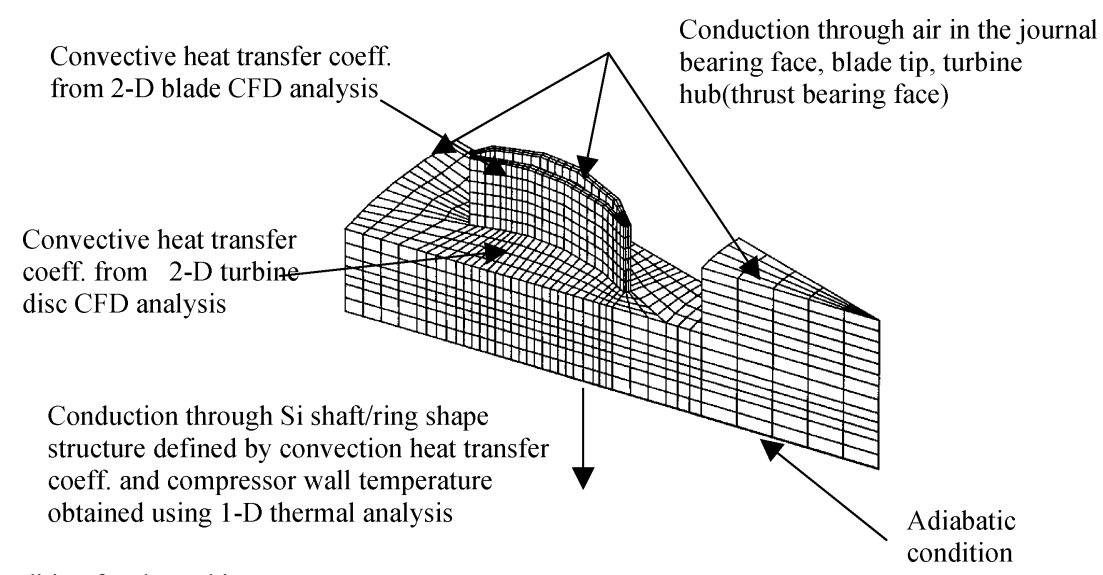

Fig. 6. Thermal boundary condition for the turbine rotor.

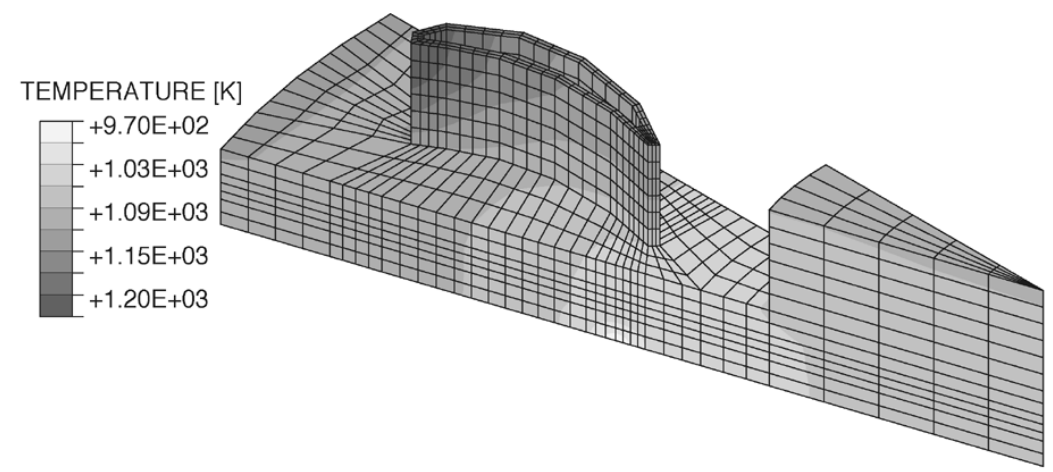

(a)

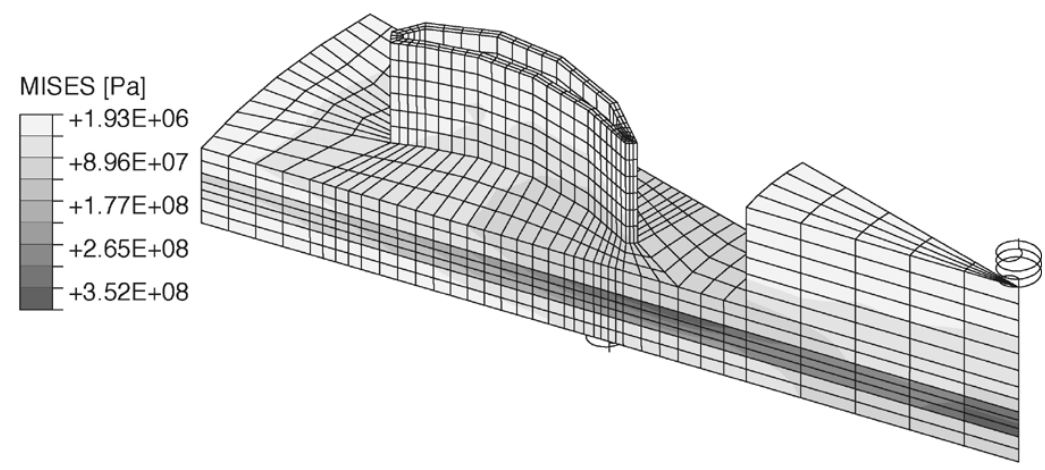

(b)

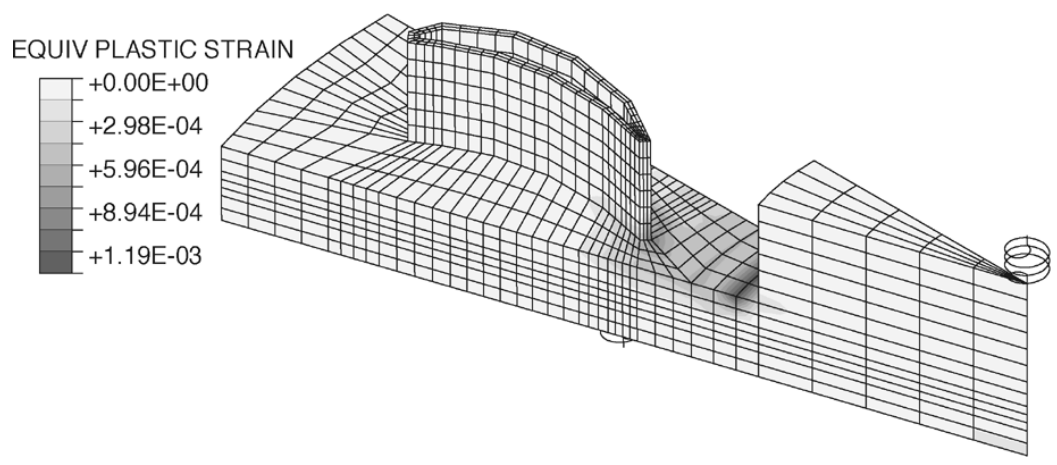

(c)

Fig. 7. Thermomechanical FE analysis results of a turbine rotor when $\left.R_{i}=1.5 \mathrm{~mm}, t_{\mathrm{wall}}=100 \mu \mathrm{m}, L_{\mathrm{shaft}}=600 \mu \mathrm{m}\right\}$, (a) temperature distribution, (b) effective stress distribution, and (c) effective plastic strain.

the shaft so that an axisymmetric FE model can be used. The thermal boundary conditions were again based on the previous analysis [21]. Fig. 8 shows the FE results of the thermal insu- lation structure between the turbine and compressor rotors in the case where $A / A^{*}=0.2\left(R_{i}=1.5 \mathrm{~mm}, t_{\text {wall }}=0.4 \mu \mathrm{m}\right.$, and $\left.L_{\text {shaft }}=0.4 \mu \mathrm{m}\right)$. The temperatures at both ends of the 


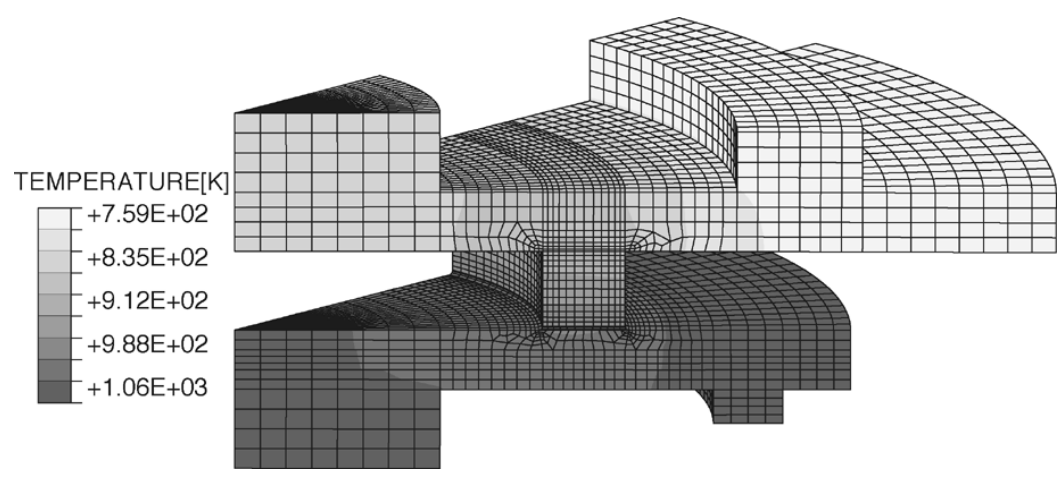

Fig. 8. FE mesh for the thermal insulation structure between the turbine and compressor disks in the case where $A / A^{*}=0.2\left(R_{i}=1.5 \mathrm{~mm}, t_{\mathrm{wall}}=0.4 \mu \mathrm{m}\right.$, and $L_{\text {shaft }}=0.4 \mu \mathrm{m}$ ).



(a)

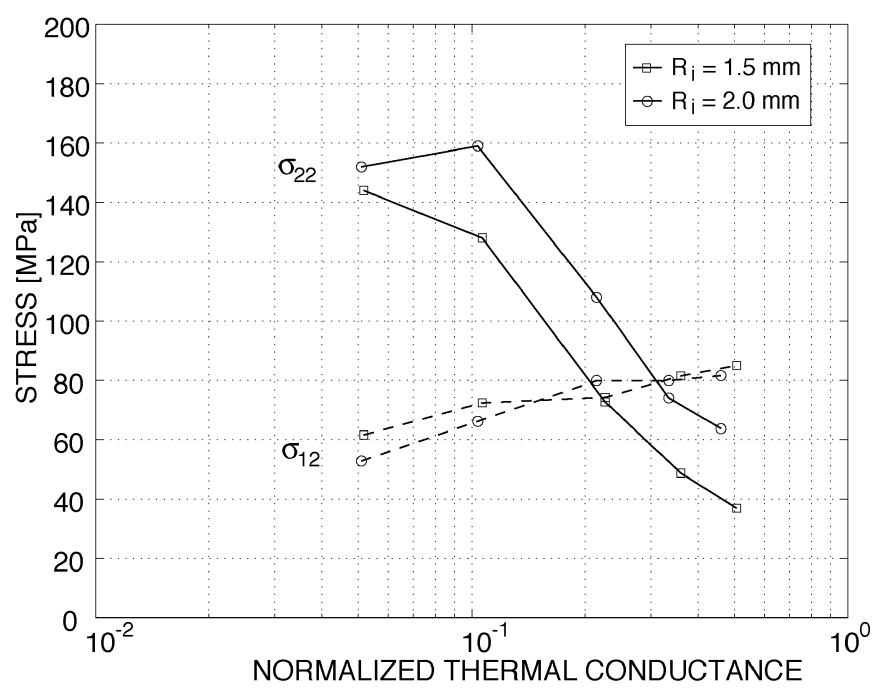

(b)

Fig. 9. Comparison for the FE results of thermal insulation structure with a 1-D cycle analysis, (a) temperatures of the both ends of the shaft and (b) stresses on the corner of the shaft.

shaft are plotted on Fig. 9(a) together with predictions using the 1-D thermal cycle analysis by Protz [3]. In Fig. 9(b), the stress states as a function of normalized thermal conductance are shown. Both the shear stress and normal stress were induced due to the bending moment from the blades and the discrepancies in the radial expansion of the turbine and compressor rotors. From the FE results, it is concluded that given the microfabrication limits, a thermal barrier structure is feasible, satisfying both thermal and structural requirements.

\section{Materials and Structures Issues in the Design of $\mathrm{Si}-\mathrm{SiC}$ Hybrid Structures}

While the initial structural analysis presented so far verified the potential of $\mathrm{Si}-\mathrm{SiC}$ hybrid structures as a medium term approach to improving the overall engine efficiency, the primary concerns associated with the mechanical behavior of Si at elevated temperatures remained unresolved. At the temperatures higher than the design temperature for the all-silicon microengine, the design of the turbine structure is likely to be limited by creep. This section assesses the structures and materials issues in the design of high temperature $\mathrm{Si}-\mathrm{SiChybrid} \mathrm{structures} \mathrm{that} \mathrm{have} \mathrm{not} \mathrm{been} \mathrm{taken} \mathrm{into}$ consideration in the structural analysis to date.
First, it is unclear whether the structural design based on the values for the yield strength of Si used in the analysis is a conservative one. Fig. 10 shows stress-strain curves for $\mathrm{Si}$ at various levels of initial dislocation density. Measurements of the upper yield strength of Si [23], [24] have also shown that the upper yield strength of $\mathrm{Si}$ is a function of temperature, strain rate, and initial density of dislocations. The key question is whether or not the structural design of $\mathrm{Si}-\mathrm{SiC}$ hybrid structures can rely on the upper yield strength of $\mathrm{Si}$, which has been adopted for the allowable stress in the analysis so far. Some of the microfabrication processes such as the CVD process and thermal cycling may induce an increase of dislocation density within the Si crystal, which in turn may reduce the usable upper yield strength. Second, it is desirable that the service life of the $\mathrm{Si}-\mathrm{SiC}$ hybrid turbine rotor be reliably estimated. At the temperatures of interest, the $\mathrm{Si}-\mathrm{SiC}$ hybrid turbine rotor is susceptible to radial growth and blade distortion due to the creep of $\mathrm{Si}$, effects which have not been accounted for in the previous FE analysis. While Walters performed a preliminary study of the Si creep and observed the localized deformation (an unexpected failure mechanism of single crystal Si consisting of slip bands), the creep parameters do not seem to be sufficiently accurate for design purpose [7], [8]. Finally, sharp corners such as blade roots or hub 


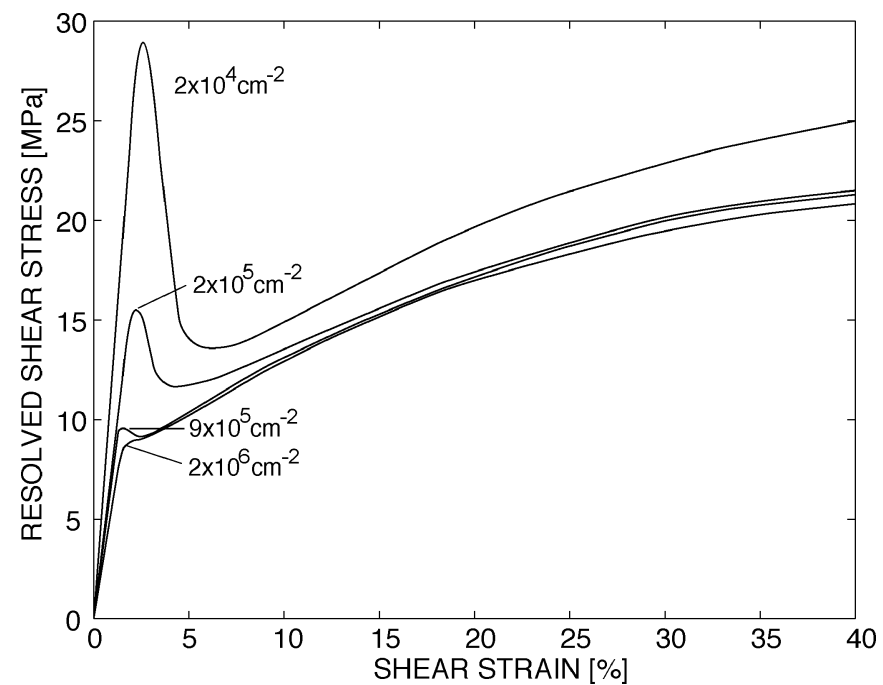

Fig. 10. Stress-strain curves of high-purity FZ-Si crystals in tensile deformation along the [123] direction as dependent on the initial density of dislocations. [K. Sumino, Deformation behavior of silicon, Metallurgical and Materials Transactions A, vol. 30A, pp1465-1479, 1999].

root, sites of high stress concentration, may be susceptible to structural instabilities when combined with the creep and strain softening of $\mathrm{Si}$.

In order to design a structure safe from these concerns, it is imperative to develop a better material model for single crystal $\mathrm{Si}$ based on more rigorous mechanical testing at high temperatures. The model developed for this purpose is described elsewhere [23]-[25]. It consists of a continuum description of the plasticity of silicon, with nominal dislocation density and shear resistance as the internal variables. The model was calibrated on uniaxial compression creep tests, and subsequently validated on four point bend data for monolithic $\mathrm{Si}$ and $\mathrm{Si}-\mathrm{SiC}$ beams. A good agreement between predictions and experimental data was achieved. In addition to the advanced Si material model, it is also crucial to assess the structural integrity of the Si-SiC hybrid structures including the interface between the Si and CVD SiC films (both the deposition and bonding interfaces) under the stresses and temperatures expected in service.

\section{Characterization of Mechanical BeHAVior of $\mathrm{Si}-\mathrm{SiC}$ HYBrID STRUCTURES}

This section discusses the mechanical testing results of $\mathrm{Si}-\mathrm{SiC}$ hybrid structures and assesses the feasibility of the hybrid structures concept for elevated temperature micro-turbomachinery.

\section{A. Mechanical Testing}

Four-point bend testing with $\mathrm{Si}-\mathrm{SiC}$ hybrid specimens as shown in Fig. 11 was chosen as a simple means to characterize the mechanical behavior of Hyper-Therm CVD SiC films at elevated temperatures and to prove the concept of $\mathrm{Si}-\mathrm{SiC}$ hybrid microturbine structures. In terms of loading similarity, the CVD $\mathrm{SiC}$ films on the outer faces of the $\mathrm{Si}-\mathrm{SiC}$ flexural specimens act as the reinforcement in a similar way to that expected in the $\mathrm{Si}-\mathrm{SiC}$ hybrid microturbine rotor under centrifugal loading. Sandwich-type specimens with various $\mathrm{SiC}$ film thicknesses

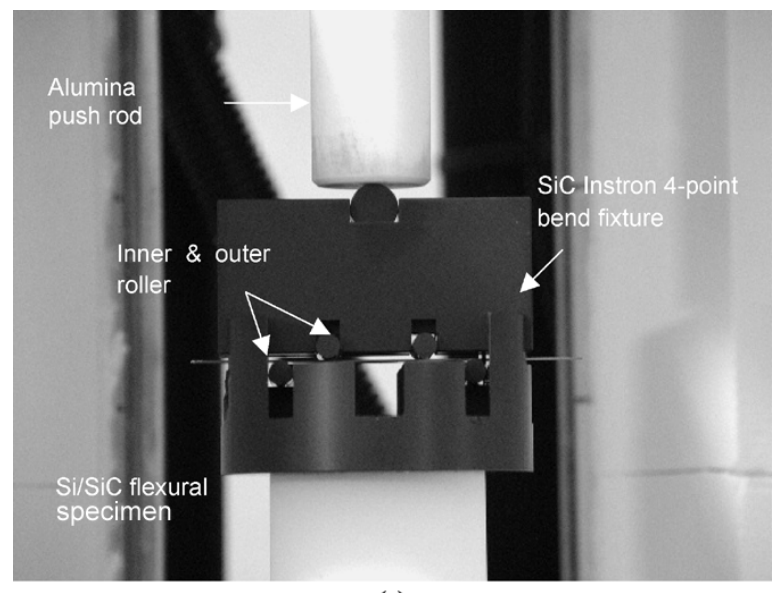

(a)

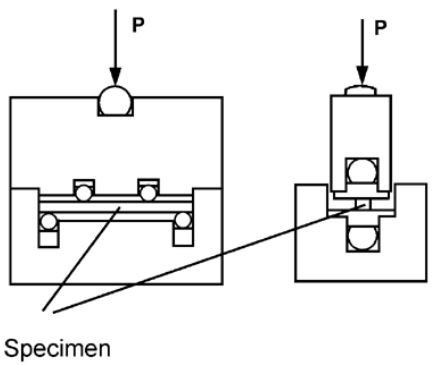

(b)

Fig. 11. (a) Four-point bend test setup and (b) schematic of the setup.



Fig. 12. $\mathrm{Si}-\mathrm{SiC}$ bend specimen after testing at $850{ }^{\circ} \mathrm{C}$ and a ram speed of $0.001 \mathrm{~mm} / \mathrm{s}$.

were used in the four-point bend tests. Fig. 12 shows a $\mathrm{Si}-\mathrm{SiC}$ flexural specimen after testing. The specimen dimensions are $0.5 \mathrm{~mm}$ thick, $8.8 \mathrm{~mm}$ wide, and $60 \mathrm{~mm}$ long. The specimen, coated with $15 \mu \mathrm{m}$ thick CVD SiC films on both sides, was loaded until fracture at $850{ }^{\circ} \mathrm{C}$ and a ram speed of 0.001 $\mathrm{mm} / \mathrm{s}$. As shown in Fig. 12, the SiC film delaminated from the Si substrate on the tension side during the test. The SEM pictures in Fig. 13 clearly show the delaminated surface of the Si substrate with a high density of striations. The counterpart of the ridges on the Si substrate can be found on the delaminated $\mathrm{SiC}$ film. This implies that the fracture occurred in the Si and that the integrity of the $\mathrm{Si}-\mathrm{SiC}$ interface was maintained during the plastic deformation at elevated temperatures. 


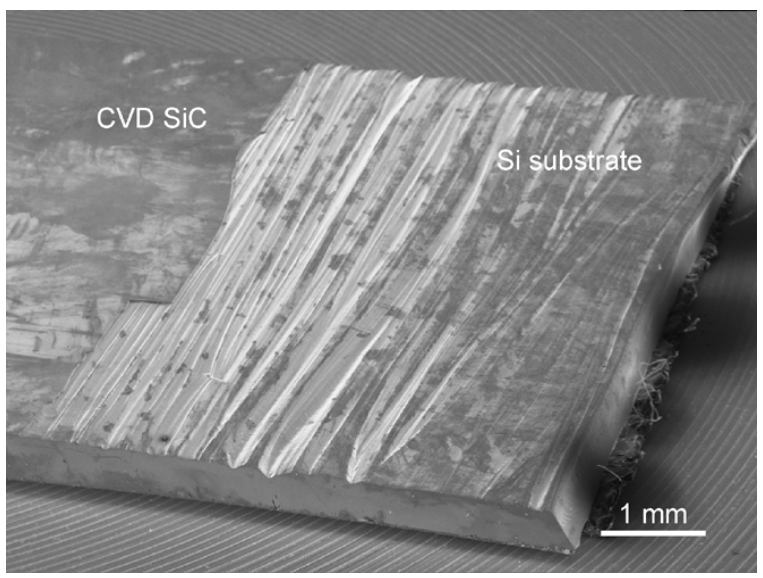

Fig. 13. SEM pictures of the $\mathrm{Si}-\mathrm{SiC}$ flexural specimen with high density of striations left on the delaminated $\mathrm{Si}$ substrate after testing at $850^{\circ} \mathrm{C}$ and a ram speed of $0.001 \mathrm{~mm} / \mathrm{s}$.

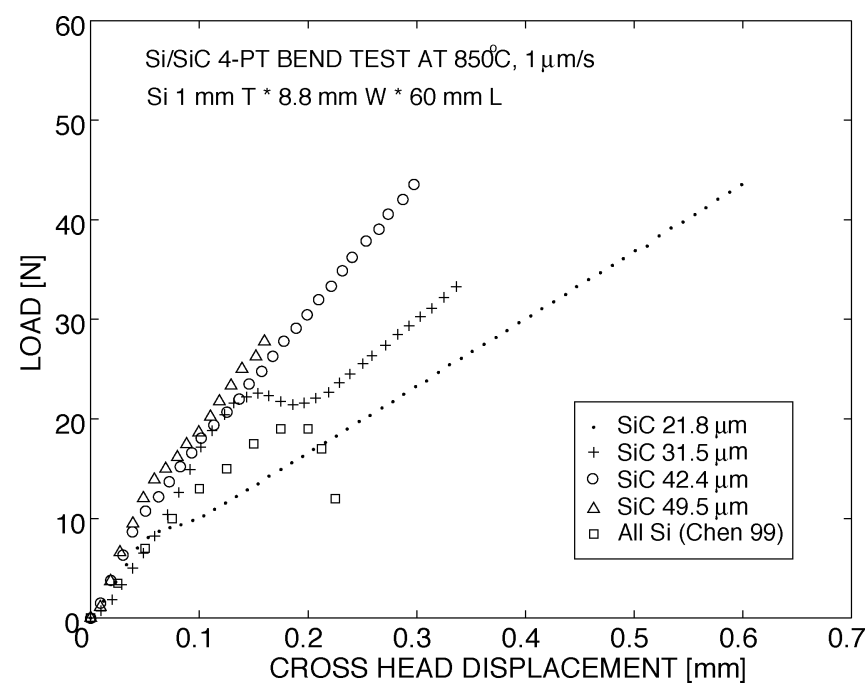

Fig. 14. Four-point bend test results of $\mathrm{Si}-\mathrm{SiC}$ hybrid specimens with various SiC film thicknesses.

Four-point bend tests of the $\mathrm{Si}-\mathrm{SiC}$ hybrid specimens were conducted for various $\mathrm{SiC}$ film thicknesses ranging from approximately 20 to $50 \mu \mathrm{m}$ at $850^{\circ} \mathrm{C}$ and $0.001 \mathrm{~mm} / \mathrm{s} \mathrm{ram}$ speed. The test results are plotted in Fig. 14. The all-silicon case is also plotted together for comparison. Each load-deflection curve changes its slope approximately at $10 \mathrm{~N}$ except for the case where the $\mathrm{SiC}$ film thickness is $31.5 \mu \mathrm{m}$. The initial slope can be obtained by the addition of the flexural rigidities of the $\mathrm{Si}$ substrate and $\mathrm{SiC}$ films. When the slope changes (or the Si substrate begins to yield), the maximum stress in the $\mathrm{Si}$ substrate is calculated to be approximately $20 \mathrm{MPa}$ using composite beam theory, which is close to the flow stress of $\mathrm{Si}$ at $900{ }^{\circ} \mathrm{C}$. From this point on, the thin CVD SiC films carry most of the load until fracture. Note that the slope after the Si yields increases with increasing the SiC film thickness.

Fig. 15 compares the model prediction of a $\mathrm{Si}-\mathrm{SiC} 4$-point bend test against the experimental data. The model accurately captures the temperature dependence originating from the plasticity of single crystal $\mathrm{Si}$ in combination with the elastic-brittle response of the $\mathrm{SiC}$. The experimental data shows the relatively slow change in the initial nonlinear behavior compared to the

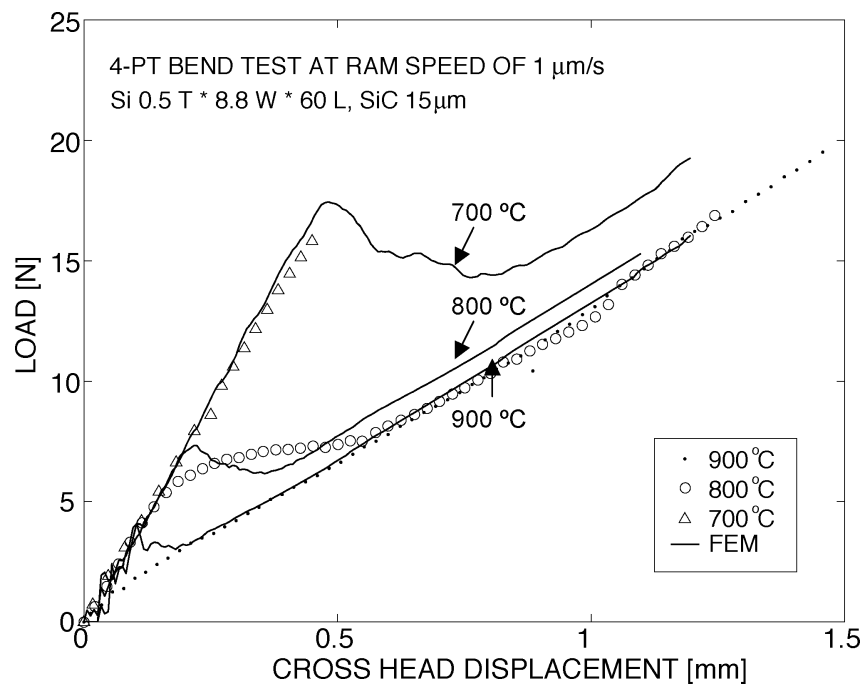

Fig. 15. Comparison of the model prediction against the four-point bend test results for $\mathrm{Si}-\mathrm{SiC}$ hybrid specimens.

model prediction. It is speculated that the dislocations nucleated in the Si crystal during the CVD process or thermal cycling during the specimen preparation may reduce the peak load level, and then the shape of the nonlinear portion of the curves. In the analysis, no further assumptions were made to adjust the increased dislocation density in the Si crystal. The model prediction of a $\mathrm{Si}-\mathrm{SiC}$ four-point bend test could be made more accurate by adopting a better assumption for the value of the dislocation density in the Si crystal.

From the experimental results and FE analysis results, it is clear that the thin CVD SiC films significantly increase the load-carrying capability of Si. While the usable load allowed by the all-silicon specimen is approximately $10 \mathrm{~N}$ (the plateau), the load that can be carried by the $\mathrm{Si}-\mathrm{SiC}$ hybrid specimens is higher by approximately a factor of three. This considerable increase in the load-carrying capacity of $\mathrm{Si}-\mathrm{SiC}$ hybrid specimens supports the overall concept of $\mathrm{Si}-\mathrm{SiC}$ hybrid structures for elevated temperature micro-turbomachinery.

\section{B. Fracture of Si-SiC Hybrid Structures}

The fracture strength of CVD SiC films is also a key issue. The average stress in $\mathrm{SiC}$ films can be estimated by assuming an Si flow stress of $20 \mathrm{MPa}$. From bending moment equilibrium, the average stress in the $\mathrm{SiC}$ at fracture was found to range from 850 to $210 \mathrm{MPa}$, with the highest for the case of the $21.8 \mu \mathrm{m}$ thick SiC film and the lowest for the case of the 49.5- $\mu \mathrm{m}$-thick $\mathrm{SiC}$ film. Although the brittle nature of $\mathrm{SiC}$ films requires Weibull probabilistic analysis to characterize the fracture strength fully, it is believed that the thicker SiC films are intrinsically weaker due to differences in the process-induced defect population. It is worth noting that the fracture strength of CVD SiC is expected to be size dependent, which is favorable for the small scale devices such as the microengine. Also, process conditions and stress-states within the structures are the key factors determining the fracture strength of brittle materials.

Sudden load drops at the failure of the load-deflection curves in Fig. 14 may imply a brittle fracture of the $\mathrm{Si}-\mathrm{SiC}$ specimens. Qualitatively, it appears that the Si substrate was subjected to 


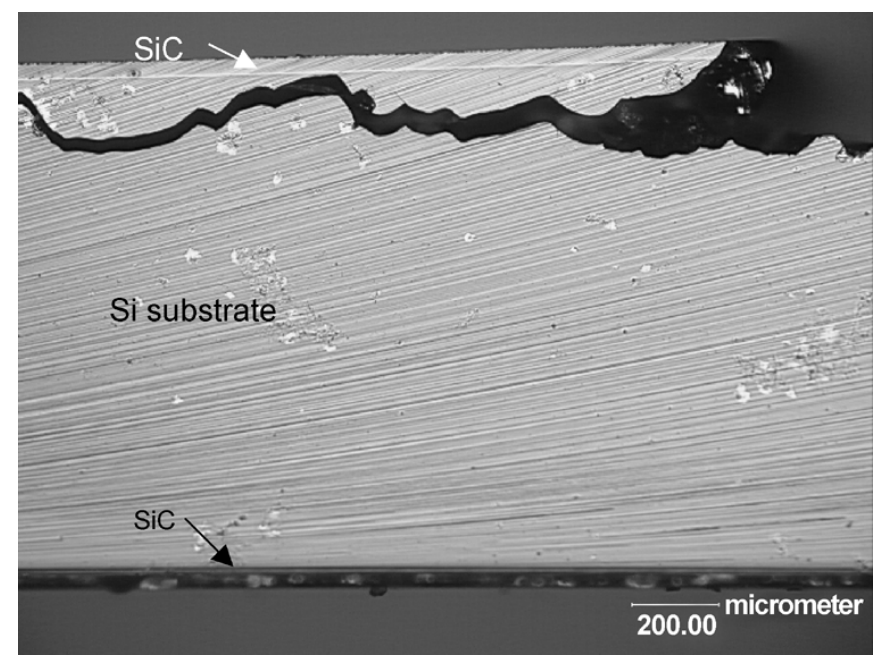

Fig. 16. Crack propagation in the Si substrate.



Fig. 17. SEM picture of a broken edge of the $\mathrm{Si}-\mathrm{SiC}$ specimen loaded until fracture at $850^{\circ} \mathrm{C}$ and a ram speed of $0.001 \mathrm{~mm} / \mathrm{s}$.

high strain rate loading due to the abrupt failure of the $\mathrm{SiC}$ film. The ductility of the Si substrate, however, does not seem to be sufficient to arrest cracks propagating from the $\mathrm{SiC}$ film or to sustain the fracture in a stable way. The $\mathrm{Si}-\mathrm{SiC}$ specimens were also examined under an optical microscope at approximately $100 \mathrm{x}$ or similar at several intermediate deflections to locate any cracks that might have developed on the $\mathrm{SiC}$ films during the experiment, but no cracks were visible. Fig. 16 shows the crack propagation in the $\mathrm{Si}$ substrate underneath the $\mathrm{SiC}$ film on the tensile side of a specimen. The shiny ridges on the Si substrate in Fig. 12 appear to be an artifact of the crack propagation. Considering that there are no indications of any precursor event before fracture, such as sudden changes of the load in the load-deflection curves, the cracks seemed to propagate rapidly at the incident of fracture. Fig. 17 also shows the broken edge of the specimen, whose clean surface implies a fracture by cleavage.

\section{REDESIGN OF Si-SiC HYBRID MICRO-TURBOMACHINERY}

Based on the knowledge derived from the experimental observations of the mechanical behavior of $\mathrm{Si}$ and $\mathrm{Si}-\mathrm{SiC}$ hybrid

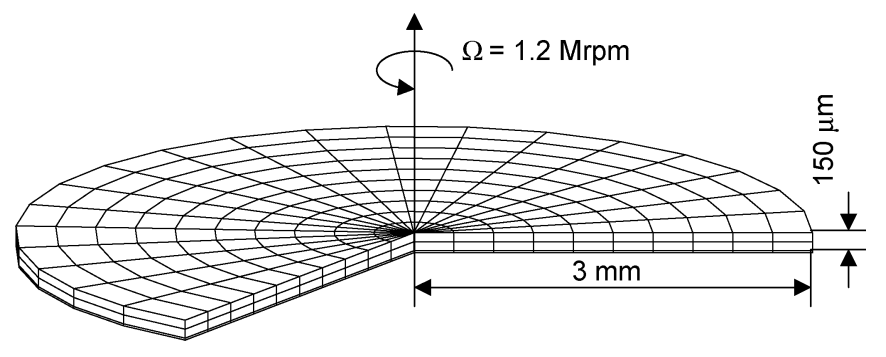

Fig. 18. Axisymmetric FE mesh to estimate the creep life of a Si-SiC hybrid turbine rotor.

structures together with the advanced $\mathrm{Si}$ constitutive model [23], [24], this section further evaluates the design of $\mathrm{Si}-\mathrm{SiC}$ hybrid structures for high temperature micro-turbomachinery.

\section{A. Creep Life Estimation of a Si-SiC Hybrid Turbine Rotor}

Miller [6] proposed a design based on a primitive material model for Si plasticity, consisting of a time independent elastoperfectly plastic behavior. In this section, the design of a $\mathrm{Si}-\mathrm{SiC}$ hybrid rotor is revisited with the Si model in order to provide a basis for reevaluating Miller's analysis.

1) FE Analysis Results for Creep Life Estimation of a Si-SiC Hybrid Turbine Rotor: An axisymmetric FE analysis was performed to estimate the creep life of the $\mathrm{Si}-\mathrm{SiC}$ hybrid turbine rotor for various $\mathrm{SiC}$ relative thicknesses ranging from 0 to $30 \%$ at elevated temperatures. ABAQUS EXPLICIT was used together with the Si constitutive model implemented in a VUMAT user subroutine. A simple sandwich-type hybrid disc model with $\mathrm{SiC}$ reinforcement in between flat $\mathrm{Si}$ discs shown in Fig. 18 was used in the analysis, as was modeled by Miller [6]. The design specifications of the current microengine rotor were considered in this analysis. The $\mathrm{SiC}$ reinforcement was described as an elastic material with a Young's modulus of $430 \mathrm{GPa}$ and Poisson's ratio of 0.21 , as reported by Jackson for Hyper-Therm CVD SiC [26]. The FE model assumes a uniform temperature distribution on the hybrid disc and a rotational speed of 1.2 million rpm. It was assumed to take $10 \mathrm{~s}$ for the rotor to reach the design rotational speed to ensure a quasistatic analysis. The turbine rotor radial growth at the rim was calculated as a function of time using this axisymmetric FE model. The maximum tensile stress in the $\mathrm{SiC}$ reinforcement was also computed. This occurs at the rotational axis.

The FE simulation results for creep life estimation of a $\mathrm{Si}-\mathrm{SiC}$ hybrid turbine rotor are shown in Fig. 19. The turbine rotor radial growth as a function of time is plotted for the four relative $\mathrm{SiC}$ thicknesses ranging from 0 to $30 \%$ for the temperatures, 700 and $900{ }^{\circ} \mathrm{C}$. The radial growth for 10 seconds corresponds to the almost entirely elastic deformation of the turbine rotor while the rotor reaches the design rotational speed of 1.2 million rpm. As shown in Fig. 19, the all-silicon turbine rotor grows significantly more rapidly than the other cases with $\mathrm{SiC}$ reinforcement. Apparently, while the amount of $\mathrm{SiC}$ in the turbine rotor limits the overall turbine rotor radial growth by creep, the turbine wall temperature determines the time taken to reach a certain level of radial growth for a given thickness of CVD $\mathrm{SiC}$ in the turbine rotor. Thus, given the allowable turbine radial growth from the system considerations, the operating conditions 


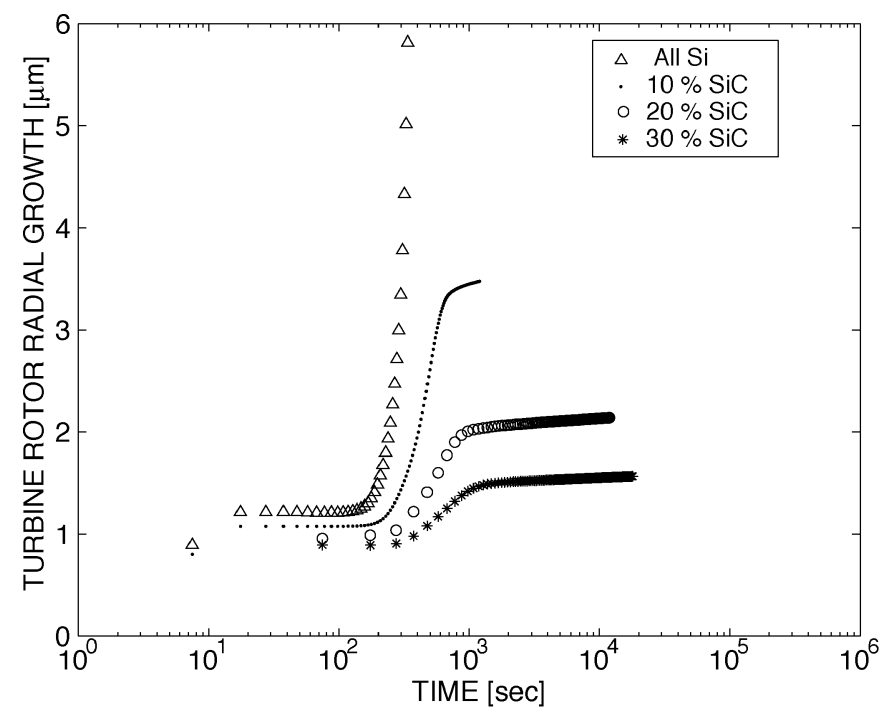

(a)

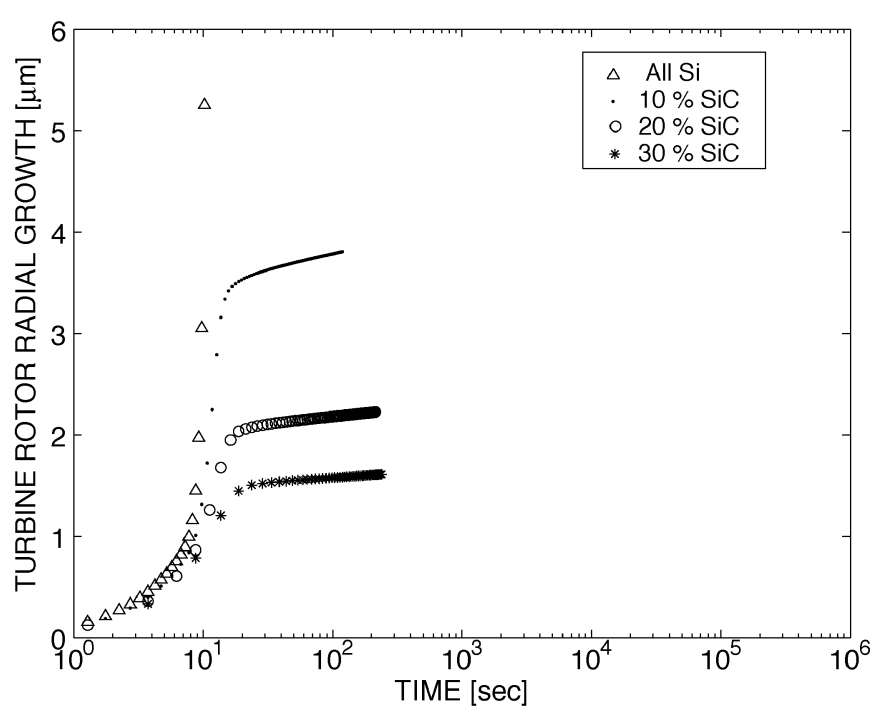

(b)

Fig. 19. Turbine rotor radial growth with time for various $\mathrm{SiC}$ relative thicknesses at various temperatures. (a) $700{ }^{\circ} \mathrm{C}$; (b) $900^{\circ} \mathrm{C}$.

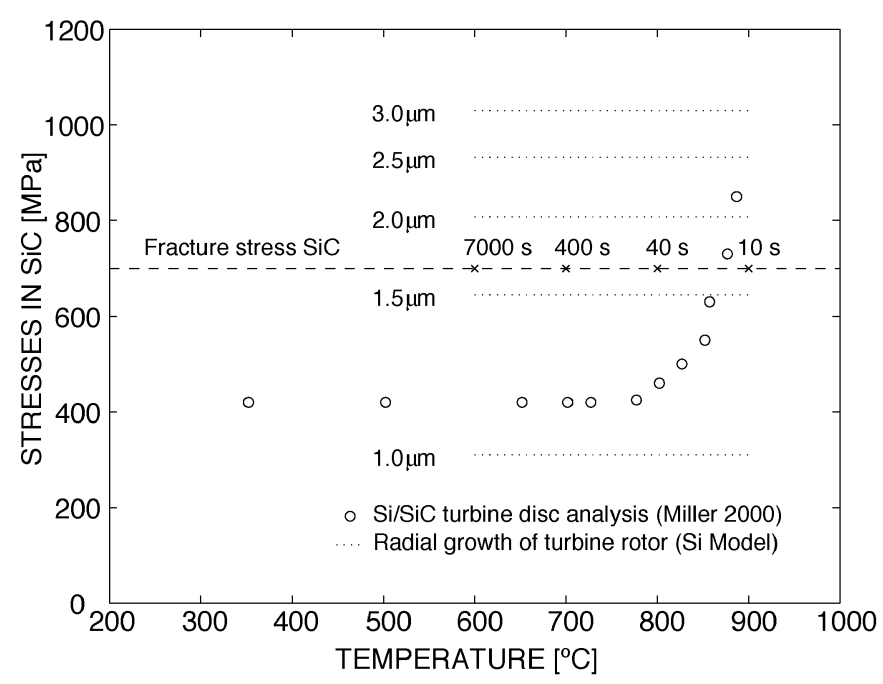

(a) $10 \% \mathrm{SiC}$

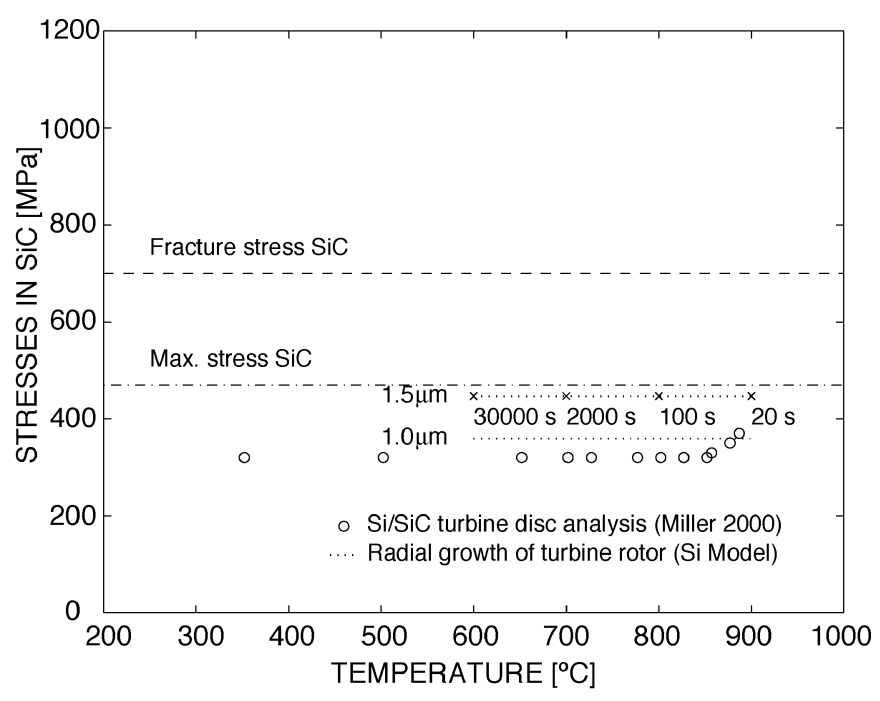

(b) $30 \% \mathrm{SiC}$

Fig. 20. Model prediction for creep life vs. elasto-plastic analysis (a) relative SiC thickness of $10 \%$ and (b) relative SiC thickness of $30 \%$.

and minimum design requirements for $\mathrm{Si}-\mathrm{SiC}$ hybrid structures can be extracted using these diagrams. In addition to failure due to creep of the $\mathrm{Si}$, fracture of the $\mathrm{SiC}$ must be considered. At the microscale the dislocations nucleated within the Si crystal under the static load (centrifugal load) soften the Si structure, and consequently cause macroscale radial creep growth. As the Si creep proceeds, the load carried by the $\mathrm{SiC}$ reinforcement gradually increases. At a certain level of the turbine rotor radial growth, the stress in the $\mathrm{SiC}$ may reach its fracture strength. This is dependent on the relative thickness of SiC. This will be discussed in more detail in the next section.

2) Comparison of the Model Prediction for Creep Life and Elasto-Plastic Analysis: In Fig. 20, the maximum stress in the $\mathrm{SiC}$ is plotted against the turbine wall temperature. These results can be compared directly with those of Miller [6]. The elastoplastic analysis shows the exponential growth of the stress in the $\mathrm{SiC}$ reinforcement with increasing temperature, but the data points are static at a given temperature. On the other hand, the stress in the $\mathrm{SiC}$ varies with time according to the model prediction at a given temperature, as the turbine radially grows with time. For the relative $\mathrm{SiC}$ thickness of $10 \%$, the stress in the $\mathrm{SiC}$ reaches its assumed fracture strength of $700 \mathrm{MPa}$ at the turbine radial growth of around $1.7 \mu \mathrm{m}$. According to the experimental results in the previous section, the $\mathrm{SiC}$ fracture strength of 700 MPa is easily achievable. However, this nominal strength represents a reasonably conservative value for design purposes. At $600{ }^{\circ} \mathrm{C}$ it takes approximately $2 \mathrm{~h}$ for the stress in the $\mathrm{SiC}$ reinforcement to reach the nominal fracture strength, and only 10 seconds at $900{ }^{\circ} \mathrm{C}$. However, for the relative $\mathrm{SiC}$ thickness of $30 \%$, the stress in the $\mathrm{SiC}$ reinforcement never reaches its fracture stress.

The elasto-plastic analysis by Miller [6] has also predicted a burst-line (temperature) for the hybrid turbine disc, beyond which the Si deforms severely and eventually bursts (numeri- 


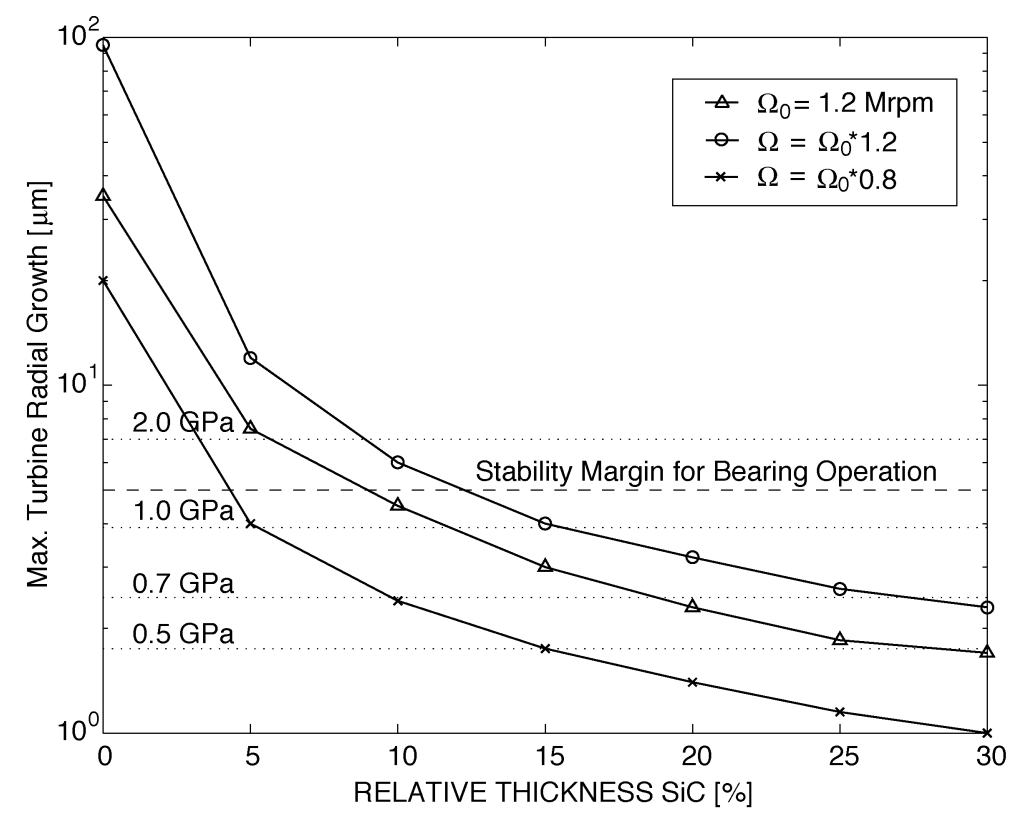

1. Rotational speed of the turbine rotor of 1.2 million rpm was used for a baseline in the analysis.

2. $10^{6}$ seconds was used as a reference time for the maximum turbine radial growth.

3. Based on the analysis over the temperature range of 600 to $900{ }^{\circ} \mathrm{C}$.

4. Stability margin for the bearing operation from Teo [27].

Fig. 21. Effect of $\mathrm{SiC}$ reinforcements on the radial growth of a Si-SiC hybrid turbine rotor.

cally the FEM, ABAQUS STANDARD, does not converge to a solution because of severe deformation of the $\mathrm{Si}$ ). According to the results in Fig. 20(b), the structural integrity of the Si-SiC hybrid turbine, however, is not limited by the $\mathrm{SiC}$ fracture strength nor by the severe deformation of the Si. Instead, the structural integrity of the hybrid turbine rotor is likely to be limited by a time scale associated with overall system considerations. For example, the turbine rotor with a $\mathrm{SiC}$ layer of $10 \%$ relative thickness lasts for only $10 \mathrm{~s}$ at $900^{\circ} \mathrm{C}$. This rotor is obviously useless. However, depending on the allowable operating time for a device, the turbine rotor with a $\mathrm{SiC}$ layer of $10 \%$ relative thickness operating at $600^{\circ} \mathrm{C}$, which will eventually fail by fracture after 3 to $4 \mathrm{~h}$, may be quite acceptable from a design point of view.

\section{B. Design Criterion for the SiC Reinforcement of a Si-SiC Hybrid Turbine Rotor}

Integrating all the information from the FE results presented in Section $\mathrm{V}-\mathrm{A}$, a criterion for the $\mathrm{SiC}$ reinforcement of a Si-SiC hybrid turbine rotor with regard to creep life is suggested in Fig. 21. The maximum turbine radial growth for the relative thickness of $\mathrm{SiC}$ was obtained from Fig. 20. Note that the relative $\mathrm{SiC}$ thickness determines the radial growth by creep almost irrespective of the turbine wall temperature. Here, $10^{6}$ seconds was used as a reference time for the turbine service life, and the data are based on the analysis over the temperature range of 600 to $900{ }^{\circ} \mathrm{C}$. Of course, depending on the reference time for the desired turbine operation, the whole curve can be adjusted, but not significantly. The dotted horizontal lines correspond to the various levels of the $\mathrm{SiC}$ fracture strength which given the relative thickness of $\mathrm{SiC}$, correspond to the maximum stress in the $\mathrm{SiC}$ reinforcement at the reference time. From system considerations, such as the requirement for stable bearing opera- tion, another horizontal line, corresponding to an allowable radial growth, can also be drawn as an additional constraint.

In order to illustrate the usage of the plot (i.e., Fig. 21), the following case was considered. Assuming the $\mathrm{SiC}$ fracture strength of $700 \mathrm{MPa}$ and the stability margin for the bearing operation of $5 \mu \mathrm{m}$, the turbine rotor needs a $\mathrm{SiC}$ reinforcement with at least a relative $\mathrm{SiC}$ thickness of $20 \%$. This configuration corresponds to a $\mathrm{SiC}$ layer of $60 \mu \mathrm{m}$ for the design specifications of the current microengine rotor. This has been demonstrated in deposition experiments [9], [10]. Note that this design requirement is relatively conservative because Fig. 21 provides the relative $\mathrm{SiC}$ thickness based on the desired turbine service life of $10^{6}$ seconds irrespective of the turbine wall temperature. The effect of the turbine rotor rotational speed was also considered. The reduction of the rotational speed by $20 \%$ allows for a thinner $\mathrm{SiC}$ layer down to the relative $\mathrm{SiC}$ thickness of $10 \%$. This result implies that the level of the $\mathrm{SiC}$ reinforcement needs to be determined from the tradeoff between the overall system requirements and the constraints imposed by the microfabrication of $\mathrm{Si}-\mathrm{SiC}$ hybrid structures. Moreover, it is clear that this design requirement on the $\mathrm{SiC}$ thickness is driven by the fracture strength of $\mathrm{SiC}$ for this case.

\section{CONCLUSION}

The design space for the structural design of the microengine turbine rotor can be extended by incorporating $\mathrm{SiC}$ in the $\mathrm{Si}$ structures. The experimental results assessed the integrity of the $\mathrm{Si}-\mathrm{SiC}$ interface during deformations at high temperatures as well as the material properties of CVD SiC. The significant increase in the load carrying capability of the $\mathrm{Si}-\mathrm{SiC}$ hybrid specimens compared to the all-silicon specimens provides more de- 
sign space for the design of the $\mathrm{Si}-\mathrm{SiC}$ hybrid turbine rotor for the next generation microengine.

The use of a simple temperature-dependent, elastic-perfectly plastic constitutive law in the initial stages of design was useful as it allowed for the relatively rapid comparison of design options. However, in validating the overall design and to perform life prediction, it is necessary to use a more sophisticated model that is capable of properly accounting for rate effects.

\section{ACKNOWLEDGMENT}

The authors would like to acknowledge A. Mracek for her assistance in conducting the experiments. The cooperation of the staff of the Microsystems Technology Laboratories (MTL), the Technology Laboratory for Advanced Composites (TELAC), and the Center for Material Sciences (CMSE) at MIT are also acknowledged.

\section{REFERENCES}

[1] H. Epstein et al., "Power MEMS and microengines," in Proc. IEEE Conference on Solid State Sensors and Actuators, 1997.

[2] K. A. Lohner, "Microfabricated Refractory Ceramic Structures for Micro Turbomachinery," S. M. thesis, Dept. of Aeronautics and Astronautics, MIT, Cambridge, MA, 1999.

[3] J. Protz, "The Design and Development of a MEMS Silicon Micro Gas Turbine Engine," Ph.D. dissertation, Dept. of Aeronautics and Astronautics, MIT, 2000

[4] A. Ayon, D. Choi, T. Harrison, E. Huang, B. Miller, H.-S. Moon, E. Noonan, S. M. Spearing, K. Turner, and X. Zhang, "Materials, Structures, and Packaging Annual Technical Report, The MIT Micro-engine Project,", Dec. 1999.

[5] K. A. Lohner, K.-S. Chen, A. A. Ayon, and S. M. Spearing, "Microfabricated silicon carbide microengine structures," in Mater. Res. Soc. Symp. Proc., vol. 546, 1999, pp. 85-90.

[6] B. Miller, "Hybrid Silicon/Silicon Carbide Microstructures and Silicon Bond Strength Tests for the MIT Microengine," S. M. thesis, Dept. of Aeronautics and Astronautics, MIT, Cambridge, MA, 2000.

[7] D. S. Walters, "Creep Characterization of Single Crystal Silicon in Support of the MIT Micro-Engine Project," M.S. thesis, Dept. of Mechanical Engineering, MIT, Cambridge, MA, 1999.

[8] D. S. Walters and S. M. Spearing, "On the flexural creep of single crystal silicon," Scripta Materialia, vol. 42, pp. 769-774, 2000.

[9] K. A. Lohner, "Microfabricated Refractory Ceramic Structures for Micro Turbomachinery," S. M. Thesis, Dept. of Aeronautics and Astronautics, MIT, Cambridge, MA, 1999.

[10] M. Mehregany, C. A. Zorman, N. Raja, and C. H. Wu, "Silicon carbide MEMS for harsh environments," Proc. IEEE, vol. 86, pp. 1594-1610, Aug. 1998.

[11] D. Choi, R. J. Shinavski, and S. M. Spearing, "Process development of silicon-silicon carbide hybrid micro-engine structures," in Mater. Res. Soc. Symp. Proc., vol. 687, Fall 2001, p. B5.44.

[12] R. J. Shinavski and W. S. Steffier, "Enhanced Strength, Nanolayered SiC for Micro Gas Turbine Portable Power Generation," Hyper-Therm Inc., 1999.

[13] J. A. Powell, L. G. Matus, and M. A. Kuczmarski, "Growth and characterization of cubic $\mathrm{SiC}$ single-crystal films on Si," J. Electrochem. Soc., vol. 134 , pp. $1558-1565,1987$.

[14] A. J. Fleischman, C. A. Zorman, M. Mehregany, C. Jacob, S. Nishino, and P. Pirouz, "Epitaxial growth of 3C-SiC films on 4-inch diameter (100) silicon wafers by APCVD," in Proc. of the Sixth International Conference, Silicon Carbide and Related Materials 1995, 1996, pp. 197-200.

[15] C.-H. Wu, C. A. Zorman, and M. Mehregany, "Characterization of polycrystalline $\mathrm{SiC}$ grown on $\mathrm{SiO}_{2}$ and $\mathrm{Si} 3 \mathrm{~N} 4$ by APCVD for MEMS applications," Mater. Sci. Forum, pt. 1, vol. 338-342, pp. 541-544, 2000.

[16] C. C. Chiu, S. B. Desu, and C. Y. Tsai, "Low pressure chemical vapor deposition (LPCVD) of $\beta$-SiC on Si (100) using MTS in a hot wall reactor," J. Mater. Res., vol. 8, no. 10, pp. 2617-2626, 1993.

[17] D. Choi, "Characterization of CVD SiC for Microengine Applications: Residual Stress Control and Microfabrication," Ph.D. dissertation, Dept. of Materials Science and Engineering, MIT, Cambridge, MA, 2003.
[18] M. A. Schmidt, "Wafer-to-wafer bonding for microstructure formation," Proc. IEEE, vol. 86, p. 1575, Aug. 1998.

[19] MSC/PATRAN Reference Manuals, 2001.

[20] ABAQUS Reference Manuals, Providence, RI, 2001.

[21] K.-S. Chen, "Materials Characterization and Structural Design of Ceramic Micro Turbomachinery," Ph.D. dissertation, Dept. of Mechanical Engineering, MIT, Cambridge, MA, 1999.

[22] B. Philippon, S. M. Thesis, Dept. of Aeronautics and Astronautics, MIT, Cambridge, MA, 2001.

[23] H.-S. Moon, S. M. Spearing, and L. Anand, "A constitutive model for single crystal Si at elevated temperature: I-model development," J. Eng. Mater. Technol., 2003, submitted for publication.

[24] - "A constitutive model for single crystal Si at elevated temperature: II-applications," J. Eng. Mater. Technol., 2003, submitted for publication.

[25] H.-S. Moon, "Design of Si/SiC Hybrid Structures for Elevated Temperature Micro-Turbomachinery," Ph.D. dissertation, MIT, Cambridge, MA, 2002.

[26] K. Jackson, R. Edwards, and W. Sharpe Jr., "Mechanical properties of thin film silicon carbide," in Mat. Res. Soc. Symp. Proc., vol. 687, Fall 2001, p. B6.3.

[27] C. J. Teo, "Personal Communications," unpublished, 2002.

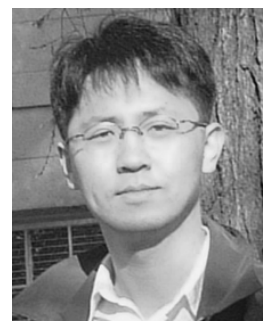

Hyung-Soo Moon received the B.S. and M.S. degrees in mechanical engineering from Seoul National University, Seoul, Korea, in 1992 and 1995, respectively, and the $\mathrm{Ph} . \mathrm{D}$. degree in mechanical engineering from the Massachusetts Institute of Technology (MIT), Cambridge, in 2002 with a dissertation on the design of $\mathrm{Si}-\mathrm{SiC}$ hybrid structures for elevated temperature micro turbomachinery.

$\mathrm{He}$ is currently a Postdoctoral Associate at MIT, mainly responsible for the materials and structures issues associated with the development of the next generation MIT Microengine. His recent research activities also include the numerical modeling of gold thermocompression wafer bonding and the development of a novel photomask for optical lithography consisting of dense arrays of nanowires/nanotubes using the self-assembly of diblock copolymer.

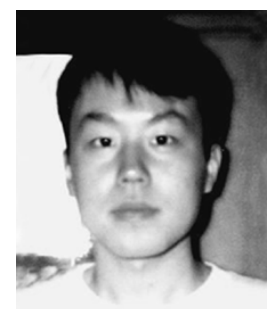

Dongwon Choi is currently a graduate research assistant pursuing the Ph.D. degree in the Department of Materials Science and Engineering at the Massachusetts Institute of Technology (MIT), Cambridge.

Since 1999, he has been with the Gas Turbine Laboratory at MIT, where he is working on silicon carbide process development for power-MEMS applications. His research interests include advanced microfabrication technologies, micro- and nanoscale materials and structures in MEMS devices, in particular, issues in deposited materials. mechanical properties, residual stresses and related

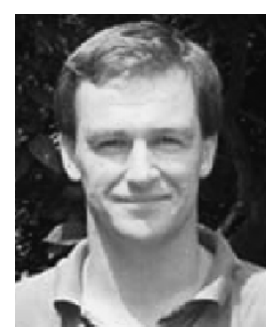

S. Mark Spearing received the Ph.D degree from Cambridge University Engineering Department in 1990

$\mathrm{He}$ is a Professor of Aeronautics and Astronautics at the Massachusetts Institute of Technology (MIT), Cambridge, where he has been since 1994. In 2004, he became a Professor of Engineering Materials at the University of Southampton, U.K. His technical interests include materials characterization and structural analysis and design of MEMS, development of wafer bonding-technologies, microelectronic and MEMS packaging and advanced composites. Since 1995 he has been responsible for materials, structural design and packaging tasks of the MIT MicroEngine, MicroRocket, Micro-Chemical Power and MicroHydraulic Transducer projects as well as conducting cross-cutting underpinning technology development. He is an editor of the JOURNAL OF MICROELECTROMECHANICAL SYSTEMS.

Dr. Spearing is a Member of the American Society of Mechanical Engineers (ASME). 